\title{
Cement-Matrix Composites Reinforced with Carbon Fibers as a Multifunctional Material
}

F.J. Baldenebro-Lopez ${ }^{1,2}$, J.H. Castorena-Gonzalez ${ }^{2}$, J.A. Baldenebro-Lopez ${ }^{2}$, J.I. Velazquez-Dimas ${ }^{2}$, J.E. Ledezma-Sillas ${ }^{1}$, R. Martinez-Sanchez ${ }^{1}$ and J.M. Herrera-Ramirez ${ }^{1}$

${ }^{1}$ Centro de Investigación en Materiales Avanzados (CIMAV), Laboratorio Nacional de Nanotecnología, Miguel de Cervantes 120, 31109 Chihuahua, Chih., México

${ }^{2}$ Facultad de Ingeniería Mochis, Universidad Autónoma de Sinaloa, Prol. Ángel Flores y Fuente de Poseidón, S.N., 81223 Los Mochis, Sinaloa, México

Carbon fibers cement-matrix (CFCM) composites are structural materials that are gaining in importance quite rapidly due to the decrease in carbon fibers (CF) cost and the increasing demand of superior structural and functional properties. The cementitious paste properties increase with $\mathrm{CF}$ volume fraction content. However, with a high fiber volume fraction the air void density becomes excessively detrimental to the mechanical properties such as the compressive strength [1]. In addition, the workability of the mix decreases with fiber content [2] while the cost increases. The aim of this investigation was to evaluate the mechanical, thermal and electrical behavior of cement-matrix composites with increasing $\mathrm{CF} /$ cement weight ratio (0.0, 0.5, 1.0, 2.0 and 3.0\%).

Mechanical behavior: The relevant properties of the structural behavior in CFCM composite are given mainly by the matrix-fiber interface stability. In the CFCM composites, the matrix fails first since it has the smaller deformation in the fracture. The fibers are mainly introduced to improve toughness and strength of the brittle matrix through their ability to interact with the mechanism that governs the toughness [3], generating several mechanisms of energy absorption controlled by the behavior of the matrix-fiber interface. In turn, this effect results firstly in the interface failure, the crack deviation and the pull-out of the fibers before the matrix failure, achieving an increase in the composite toughness.

Thermal behavior: The thermal conductivity of CF is one or two orders of magnitude higher than that of the cement-matrix. Surface temperature measurements with a thermographic camera were performed in composites samples to identify their thermal behavior after CF addition. The measurements were carried out at room temperature and after $15 \mathrm{~min}$ of exposure to $200{ }^{\circ} \mathrm{C}$. According to the results, the thermal conductivity of CFCM composites is reduced by increasing the CF content. This effect is attributed to the increase in the air void content within the matrix as a function of the CF concentration. Additions of $\mathrm{CF}$ to cement paste lower the thermal conductivity, thus allowing potential applications related to thermal insulation.

Electrical behavior: The electrical conductivity of $\mathrm{CF}$ is eight orders of magnitude greater than the cement-matrix. As a result, the electrical conductivity of CF-cementitious paste composites is increased with the carbon fiber addition in spite of the increase in air void content; this enhancement in electrical conductivity is due to the high amount of CF allowing more contact among them.

References:

[1] Chen P, Fu X and Chung DDL, ACI Mater J, 94 (1997), p. 47.

[2] Park SB and Lee BI, Cem Concr Composites, 15 (1993), p. 53.

[3] C Yao, M Nakashima, Earthquake Engineering and Engineering Vibration, 11 (2012), p. 11. Acknowledgements: This work has been supported by CONACYT, CIMAV, UAS and PROFAPI 2013/41. 

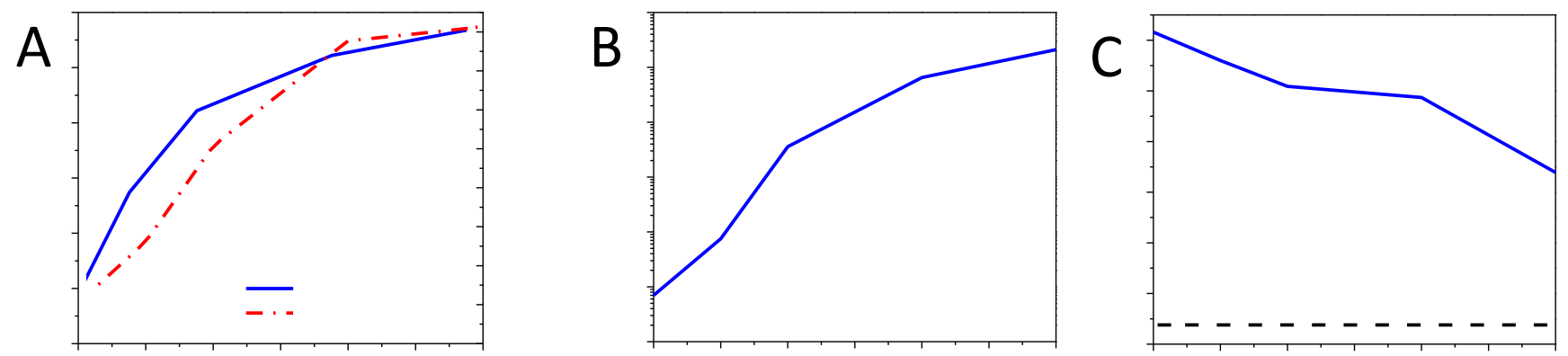

Figure 1. Influence of the fiber content of cement pastes on (A) tensile and flexural strength, (B) electrical conductivity and $(\mathrm{C})$ thermal behavior.
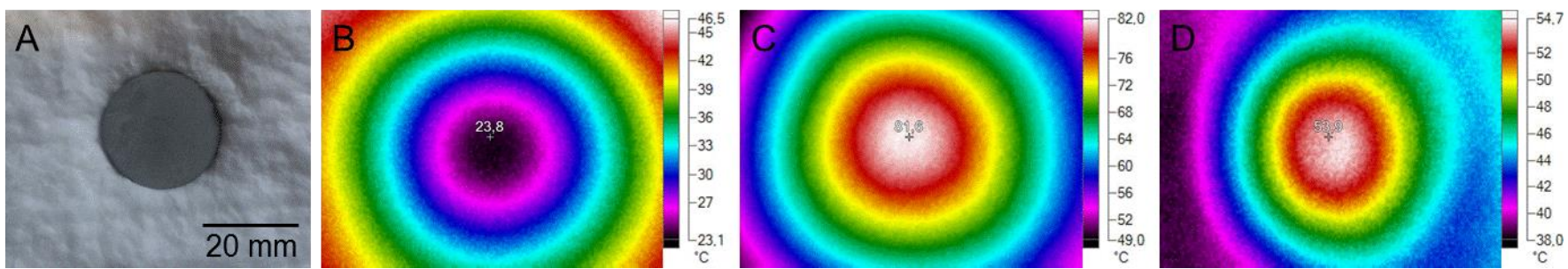

Figure 2. (A) Image of the surface cylindrical sample. Thermographic images of cementitious samples with $0.0 \% \mathrm{CF}$ at: (B) room temperature and (C) after heating. (D) $\mathrm{CFCM}$ with $3.0 \% \mathrm{CF}$ after heating.

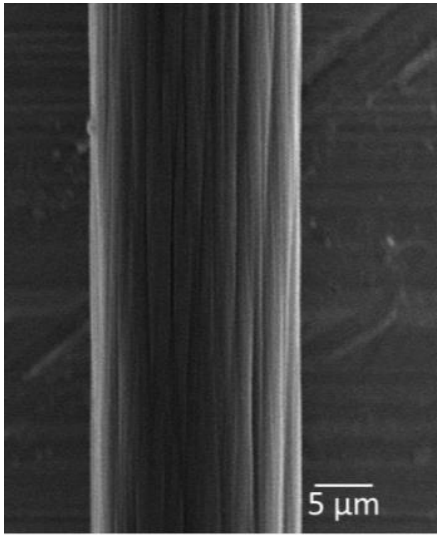

Figure 3. SE-SEM image showing texture and diameter of a carbon fiber.
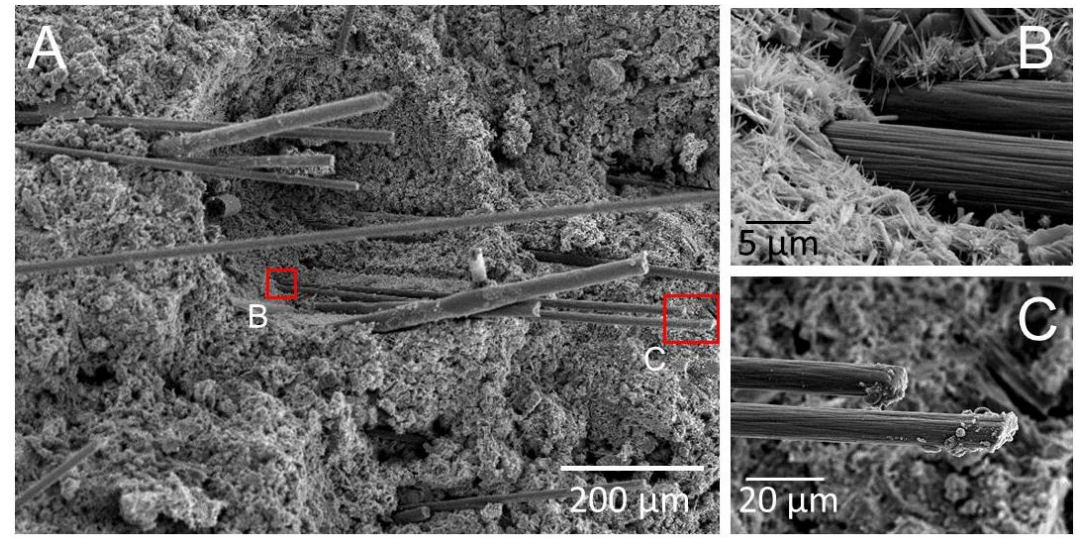

Figure 4. SE-SEM images of (A) fracture of a carbon fibers cementmatrix composite. Close-up view of (B) fibers immersed in cementmatrix after fracture, and $(\mathrm{C})$ carbon fiber failure.
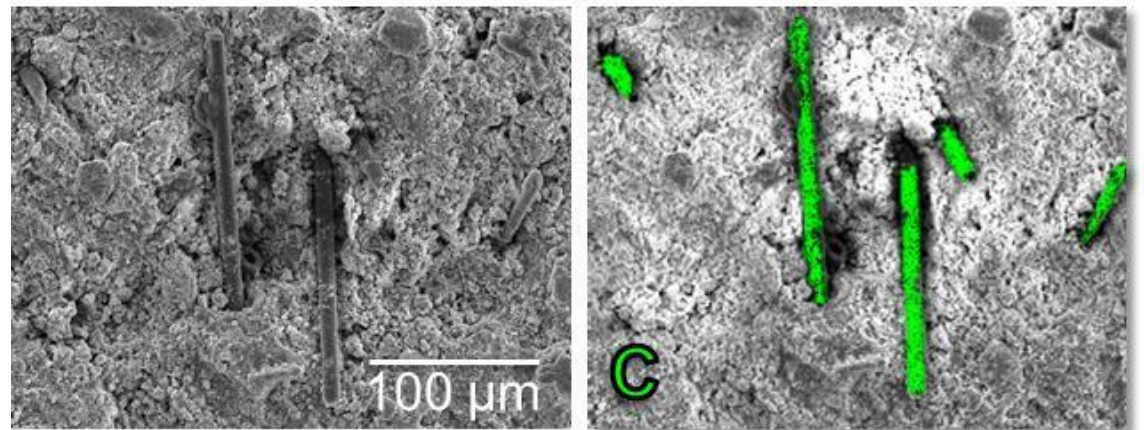

\begin{tabular}{||c|r|}
\hline Element & $\boldsymbol{W t} \%$ \\
\hline $\mathbf{C}$ & 14.33 \\
\hline $\mathbf{O}$ & 13.83 \\
\hline $\mathbf{M g}$ & 1.31 \\
\hline $\boldsymbol{A l}$ & 1.80 \\
\hline $\mathbf{S i}$ & 10.56 \\
\hline $\mathbf{S}$ & 1.85 \\
\hline $\mathbf{C a}$ & 54.06 \\
\hline $\mathbf{F e}$ & 2.26 \\
\hline
\end{tabular}

Figure 5. SEM-EDS mapping images showing the carbon distribution to identify the carbon fibers in the cement-matrix. The table indicates the elemental content of the composite. 